\title{
KULEUVEN
}

WP EN2012-03

\section{Forum shopping for ex-post gas-balancing services}

Nico Keyaerts, William D’haeseleer

TME WORKING PAPER - Energy and Environment Last update: January 2014

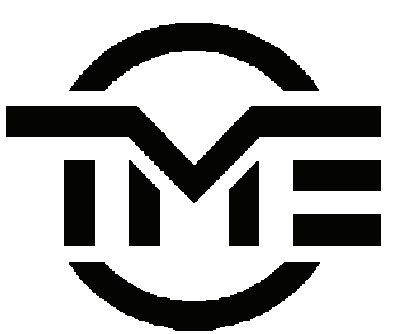

An electronic version of the paper may be downloaded from the TME website:

http://www.mech.kuleuven.be/tme/research/ 


\title{
Forum shopping for ex-post gas-balancing services
}

\author{
Nico Keyaerts and William D'haeseleer* \\ University of Leuven (KU Leuven) Energy Institute, TME branch (Applied Mechanics \& Energy Conversion), \\ Celestijnenlaan 300A P.O.Box 2421, B-3001 Heverlee, Belgium. \\ * Corresponding author: Tel +32 163225 11; Fax +32 163229 85, \\ Email: nico.keyaerts@mech.kuleuven.be (Nico Keyaerts) \\ william.dhaeseleer@mech.kuleuven.be (William D’haeseleer)
}

\begin{abstract}
The patchwork of different imbalance-settlement rules in geographically adjacent gas regions induces shippers to go "forum shopping" to minimize costs of ex-post balancing services. This shopping increases efficiency, and thus welfare of the shippers, on the one hand. The impact on net efficiency is dependent on the relative incentives provided by different balancing mechanisms and the relative system-balancing costs that the transmission-system operators face to offer balancing services to unbalanced shippers, on the other hand. If the gas-balancing mechanism and the system-balancing costs are aligned, net efficiency in the combined gas system will rise. Our results demonstrate that such an outcome is not guaranteed. Hence, market integration without properly checking compatibility of balancing rules can improve shipper efficiency at the cost of reducing overall efficiency. The latter outcome should clearly be avoided by policy makers and European regulators whose primary concern should be overall efficiency as this provides fair and efficient prices for gas consumers and a higher utility for society.
\end{abstract}

Key words: efficiency, gas balancing, cross-border regulation

\section{Introduction}

In liberalized and unbundled gas markets the coordination between different functions in the gas-supply chain becomes more challenging. Yet, this coordination makes up a cornerstone of reliable day-to-day gas-system operation. The European approach to restructure the gas system follows the line of the electricity-system liberalization: breaking up vertically integrated utilities in competitive (gas production, import and sale) and non-competitive regulated activities (transport and distribution). Flexibility, on the other hand, belongs to a twilight zone: competitive in principle, but in Europe it remains to a large extent regulated. The safe and efficient operation of the gas system depends then on the optimal combination of gas supply, transport and flexibility and it involves different actors - the shipper and the gas-transmission-system operator (TSO) - who are 
subject to different rules. Therefore, a coordinating interface between these functions is required: this is the "balancing mechanism". Furthermore, the multi-region European gas market has been integrated; meaning transnational shippers are becoming active in multiple balancing regions. The study of the multi-region gas market has two approaches: first, the design of the regions in the multi-region gas market can be studied, which is briefly discussed below, but is not further investigated in this paper; or the coordination of market players by two sets of rules can be looked at, which is the approach taken in this paper.

Although the objective of the EU legislation is to create a common market for gas, the EU gas market is not a single market. Indeed, borders remain present within the area covered by that EU legislation. For historical reasons, these demarcated zones correspond mainly to national markets or smaller geographical areas that have been controlled by a historic monopolist utility company. As a result, these demarcated geographical regions often have no economic or technical justification and the presence of a multitude of (too) small zones, e.g., with regard to the consumption or the amount of traded gas, has been found to hamper new entry (European Commission DG Competition, 2007). At the same time, removing all barriers to create a single market area is not achievable at this time due to technological, e.g., pressure management and congestion, and possibly also organizational limitations and costs. Therefore, the design and organization of the multiregion gas market, including the sizing of market areas and balancing zones has been, and still is a topic of interest for the regulators, TSOs and other gas-market participants. Different possible gas-market models have been developed by, e.g., Ascari (2011), Glachant (2011), Moselle and White (2011), Clingendael (2011), and Frontier Economics et al (2011). Note that these models represent target models to be achieved on a horizon of 10-15 years and that they represent different visions on the market design. Ascari (2011), for instance, presents a market model, that draws from the organization of the US gas market and is relying on the interactions between market forces - as in the US gascommodity and gas-transport markets - and regulation to organically achieve a functioning organization of the EU gas market, whereas the other models remain closer to the present institutional framework of the EU gas market. For a discussion on the main differences between the models see, e.g., Ascari and Glachant (2011) and Glachant (2012). Finally, the European regulators have published their vision on a European target model for the gas market (CEER, 2011). This CEER target model reflects the main principles of the MECOS (Market Enabling, COnnecting and Securing) model developed by Glachant $(2011 ; 2012)$. In the discussion below, the focus is on those aspects of the MECOS model that are relevant to the organization of balancing. The full details of the model, however, should be consulted in the original work. 
With regard to the sizing of market regions, and balancing zones, the MECOS model suggest two ways of rethinking the currently too small market regions to obtain functioning wholesale markets. A functioning gas market is then defined as " $a$ single price zone that is accessible to incumbents and new entrants on equal terms and where trading is liquid..." (Glachant, 2011, p. 13). Furthermore, a number of key indicators to estimate the functionality of a market are presented: e.g., a Hirschmann-Herfindahl Index (HHI) of below 2000, participation of at least three producers and a great many gas consumers combining for a total consumption of about 20 billion cubic meters (BCM), and presence of at least three entry points into the zone. ${ }^{1} \mathrm{~A}$ first design option to obtain functioning markets consists of the "market area model". In this model, well connected transmission and distribution networks in a geographical area are organized in a single entry-exit zone. This single zone serves then as a virtual market place and has a single balancing mechanism with one set of rules for the area. The alternative design option consists of the "trading region model". In this model, a number of TSOs establish a common entryexit zone on the supranational transmission level, while keeping national balancing zones for the end users. The common entry-exit zone, again, serves as a virtual trading point for both the supranational and national levels. With regard to balancing, this second model does not require a single set of balancing rules in the different balancing zones. Furthermore, the participating TSOs could establish a single balancing entity or the TSOs keep separate accounts of trades on the supranational level. The balancing of shippers is then effectively carried out on the level of the national balancing zone. The choice for either of the design options and the number of remaining borders - or, alternatively, the size of the market regions - will be the result of a cost-benefit analysis with regard to the organizational and physical reality that has to be dealt with. Furthermore, the two design options can co-exist in the resulting multi-region gas market.

This paper focuses on the coordination by rules in a postulated multi-region gas market. First, it is demonstrated that shippers/suppliers can make a profit by "forum shopping" between different sets of imbalance-settlement rules in different balancing regions. ${ }^{2,3}$ In

\footnotetext{
${ }^{1} \mathrm{HHI}$ is a measure of market concentration obtained by adding the squared market shares, expressed in percentage points, of the market players.

${ }^{2}$ Although in the liberalized gas market supply - trading the commodity - and shipping - using the gastransmission grid - are two distinct activities, the two roles are often closely integrated. Therefore, only one entity is considered, referred to as "shipper". Further distinction is made whenever this is necessary for clarity.

3 "Forum shopping" is a concept originally used in the legal world referring to the practice of choosing the jurisdiction to affect the expected outcome of a ruling (Juenger, 1989). In this paper, this concept is transposed to the gas system referring to the behavior of shippers to move imbalances to the system with the more lenient balancing mechanism.
} 
other words, forum shopping pays for the shipper if there is no single price for imbalance services in geographically adjacent gas markets as is the case in a multi-region gas market, like in Europe, that handles imbalance settlement differently in different balancing regions. Second, the analysis investigates what the impact is on total efficiency of the shippers who are the users of balancing services, on the one hand, and the transmission system operator who provides the balancing service to the shippers in his balancing region, on the other hand. Policy makers have to be aware that this net efficiency can decrease, as will be demonstrated in the main part of this paper, and regulators should actively check compatibility of rules in adjacent regions, especially because there is currently no market mechanism to auto-correct arbitrage profits. To make the analysis, a case study is carried out for the Belgian and UK imbalance-settlement designs, but the results are more general as both designs represent the main design differences in Europe: settlement with (Belgium) and without (UK) intra-period constraints and tolerances. Hence, the identified arbitrage opportunities are present between many European balancing regions: e.g., Austria has hourly balancing, Belgium and Germany have daily balancing with hourly constraints, France and Spain have daily balancing with some tolerance for an amount of daily imbalance, and the UK has daily balancing without any tolerances (KEMA, 2009; Keyaerts, 2012a; Keyaerts et al., 2011). As soon as fundamental differences are present between two balancing-mechanism designs - even when they are not geographically adjacent, there is a potential for arbitrage.

Academia have made a limited contribution to the debate on the issues of gas balancing because the problem is recent, only becoming relevant due to the market reforms to liberalize the gas markets in Europe, and because the problems are specific to the EU context of non-competitive transport-services markets and entry/exit regulation in zones as opposed to point-to-point competitive pipelines in the US. These concepts are further, explained below. Keyaerts et al. (2011) provides a general introduction to the gasbalancing problem and shows that current European balancing rules regulate line-pack flexibility, which is often the main balancing instrument for the TSO, in an inefficient way, distorting both the competitive and non-competitive parts of the gas market. Hallack (2011) has discussed the regulation of flexibility in the context of changing needs in the European gas market. These changing needs, like more intra-day flexibility for gas-fired electric power plants (GFPPs), change the operation of the gas network. Indeed, in that case, the gas network will be used more flexibly for balancing gas demand and supply. The current regulation of gas networks is thus challenged. Codognet (2004), furthermore, has analyzed the role of the shipper as the pivotal market player who builds a portfolio of supply, demand and flexibility contracts. Codognet (2006) has also discussed the role of institutions for gas-network access. He has identified the balancing rules as one of three 
dimensions that determine proper access to gas markets. Hence, the design of balancing mechanisms is important from a technical point of view - ensuring gas-system reliability and from an economic point of view - market access and market functioning. Crossborder aspects of balancing have been studied for the electricity sector by Vandezande (2011; 2009). In those works, it is demonstrated that current electric load balancing creates profit opportunities for balancing responsible parties in the electricity market. This paper presents a similar analysis, but applied to the gas market. In a wider gasmarket context, academia have investigated cross-border interactions in the framework of long-term import contracts and import dependency (e.g., Asche et al., 2002; Glachant and Hallack, 2009; Jansen et al., 2004; Lise et al., 2008; Stern, 2009; von Hirschhausen and Neumann, 2008), or shorter-term convergence of hub prices (e.g., Asche et al., 2006; Asche et al., 2002; Brown and Yücel, 2008; De Vany and Walls, 1996; Doane and Spulber, 1994; Neumann et al., 2006). In the European gas industry, on the other hand, balancing has been a controversial topic since the start of the liberalization process. Starting with some basic principles in the early 2000s (CEER, 2003), the European Regulators Group for Electricity and Gas (ERGEG) arrived at non-binding guidelines for gas balancing (ERGEG, 2006), which define a set of principles for designing a balancing mechanism. However, these principles were perceived by the industry as too vague and not providing a clear direction. KEMA (2007) advocated a daily balancing period and market-based balancing charges in their report for the German energy regulator. NERA and TPA Solutions (2005) conclude from an extensive review of different balancing-mechanism implementations that clear common balancing principles would move the liberalization forward. European regulators (ERGEG, 2005, 2006, 2007, 2008) and gas transmission operators (GTE, 2001, 2005,2009 ) have published many position papers even though a clear proposal for a common balancing mechanism design was never laid down. Meanwhile, KEMA (2009) has argued that the lack of market-based balancing mechanisms potentially constitutes a barrier to cross-border trade and thus to market integration. They further identify a number of design parameters such as balancing charges and the balancing period that can distort gas-market development. ERGEG (2010) has proposed a target model for a common European balancing mechanism. This model has served as a draft framework to re-open the long-lasting discussion. Although the views are not very different from those expressed in earlier position papers, the virtue of this draft framework consists in the firmer language (e.g., actually referring to a "target model") it uses. Finally, the Agency for the Cooperation of Energy Regulators, continuing the work of ERGEG, has introduced formal framework guidelines that are currently being converted into network codes by the European transmission system operators (ACER, 2011). The level of controversy still surrounding gas balancing in Europe contrasts with approaches in other gas markets. In the US, the balancing problem has been fundamentally settled by FERC Order 637 (FERC, 
2000), on the one hand; and by the development of a proper flexibility market based on heterogeneous contract bundles of geographical and time flexibility combined with pointto-point transport services offered by competing pipelines, on the other hand (Hallack et al., 2010). In Europe, the costs of ex-post flexibility services are (partly) socialized and the bundling of network flexibility and transport services is homogeneously governed for all shippers by the network code and balancing rules covering a geographical area consisting of multiple connected pipelines (Keyaerts et al., 2011).

From a methodological point of view, regulatory economics and adapted welfare economics are combined with an optimization model to determine the efficiency of the profit-maximizing transnational shipper who relies on ex-post balancing services to match demand and supply. ${ }^{4}$ First, the viewpoint of the shipper is taken, determining the arbitrage opportunities by using a forum-shopping strategy compared to an autarkic strategy. To this end different imbalance-settlement mechanisms are modeled and compared with reference to the costs of ex-post balancing. In a second step, the viewpoint of the TSO is taken to assess the efficiency of TSOs in balancing their region. Finally, the net efficiency impact is discussed for different relative balancing costs in the efficient and expensive region. The main part of the paper is then structured as follows: the second section explains the basic design options for the balancing mechanism. In particular, the balancing period and the balancing charges are highlighted. Section three puts forward the used methodology and assumptions. In the fourth section, the efficiency impact of forum shopping compared to autarky is discussed. First, the shipper surplus is determined, followed by an analysis of the system operator's efficiency changes. In the final part, summarizing conclusions and policy implications for ex-post balancing services are laid out for further discussion.

\section{Gas balancing mechanism: theoretical definition and practice}

A gas-balancing mechanism serves two main purposes. The primary objective is to transfer the financial responsibility for ex-post balancing services to unbalanced shippers by means of balancing charges. These charges should, in principle, reflect the actual balancing costs for the system operator. Keyaerts et al. (2011), though, have demonstrated that cost reflection is rarely attained in current balancing mechanisms, at least not in a transparent manner. The second objective consists in incentivizing shippers to balance ex ante, often by means of a non-cost-reflective penalty for unbalanced positions. It is argued in this paper that differences in balancing-mechanism design across

\footnotetext{
${ }^{4}$ Ex-ante flexibility means the flexibility contracted by the shipper beforehand, whereas ex-post flexibility refers to flexibility provided by the TSO to cover shipper imbalances (Keyaerts et al., 2011).
} 
borders induce shippers to go shopping for ex-post-balancing services. All of this is demonstrated in section three, but first the balancing mechanism has to be defined.

\subsection{The balancing mechanism as a 3-dimensional construct}

Keyaerts et al. (2011) point out that physical balance of the system is dependent on the pressure management and that inherent line-pack flexibility adds a storage term to the physical balancing equation. A physical difference between injection and withdrawal, therefore, does not automatically imply a problem for the gas system because the internal (pressure-related) pipeline flexibility physically covers unbalanced flows. This makes the gas system very different from the electricity system, which has to be balanced instantly. Keyaerts et al. further specify that pipeline flexibility is limited due to physical constraints, on the one hand; and due to an economic trade-off between using pipeline capacity to offer transport services or flexibility services, on the other hand. Physical disequilibrium of the gas system only becomes a problem when it persists over longer time intervals; hence, current gas-balancing mechanisms define imbalances economically as differences between the amount that has been injected by a shipper and the amount that has been offtaken, disregarding whether the physical system is affected or not.

Basically, a balancing mechanism is a three-dimensional construct (Fig. 1). The main dimension, evidently, accounts for the balancing charges, represented by "settlement" in Fig. 1 . These charges relate to imbalances that are to be defined first by demarcating a two-dimensional balancing playing field. This playing field establishes the geographical and time flexibility in a balancing zone in the European gas market.

The first dimension covers the demarcation of a geographical balancing zone ("space" in

Fig. 1). One balancing zone corresponds to one balancing-mechanism design. Ultimately, complete gas-market integration would be reflected in the removal of all spatial limitations with regard to balancing, meaning that the European gas system becomes a single balancing area. Currently, technical grounds preclude a balancing zone of such size as the pressure management would become uncontrollable without massive investments. Therefore, smaller territories are delimited and often these territories coincide with countries. Some national gas systems have been consisting, or still consist, of multiple balancing zones: this is the case in Belgium, France and Germany. Consequently, shipper imbalances are calculated by balancing zone, meaning that gas entering an area should match gas leaving that area. 


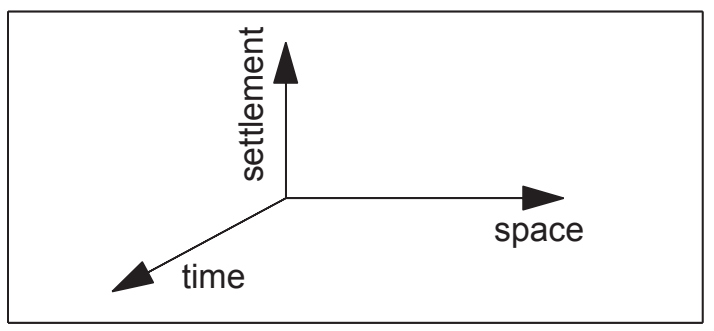

Fig. 1: Balancing mechanism as a 3D-construct of time (balancing period), space (balancing area) and settlement (balancing price)

The second dimension of the balancing playing field deals with time. Because of the previously explained line-pack buffer, instant balancing of the gas system is not required and imbalances are defined over a chosen time interval. ERGEG (2010) advocates a daily balancing period, meaning that aggregate gas injection and withdrawal should only match at the end of each gas day, but hourly (e.g., Austria) and even monthly balancing (FERC, 2000) can exist too. Unmatched injections and withdrawals within the formal balancing period are not considered imbalances within the balancing mechanism. However, these mechanisms often include other balancing frequencies or cumulative definitions of an imbalance to provide additional balancing incentives to shippers on an intra-balancing period basis.

In summary, the balancing period and balancing zone demarcate the balancing playing field and, subsequently, they confine the definition of imbalances within the balancing mechanism. ${ }^{5}$ An imbalance is thus defined as the difference between aggregated gas injection and withdrawal in a balancing zone at the end of the balancing period compared to the beginning of the period. The balancing playing field also determines adequacy and availability of different flexibility instruments for ex-ante and ex-post balancing. Storage, for instance, is a major source of flexibility, but only storages with high injection and withdrawal rates seem plausible balancing-service providers. As Keyaerts et al. (2011) point out the, balancing period is closely related to the amount of line-pack flexibility at the disposal of the system operator. The latter needs to cover all imbalances within the balancing period; the longer the balancing interval lasts, the bigger this responsibility becomes.

\footnotetext{
${ }^{5}$ Imbalance charges are based on energy ( $\mathrm{MWh}$ ), but in this paper $\mathrm{M} \mathrm{m}^{3}$ (million cubic meter) is used, which is the typical unit for gas flow analysis. Conversion between both units is straightforward by assuming a single caloric value, e.g., $0.0115 \mathrm{MWh} / \mathrm{m}^{3}$.
} 


\subsection{Balancing charges}

Any balancing mechanism defines balancing charges to settle unbalanced shippers. The complexity of the balancing-tariff structure, though, strongly varies between balancing zones. Balancing charges should be market based and reflect actual system-balancing costs (ERGEG, 2010; KEMA, 2009). Keyaerts et al. (2011) note that balancing charges often refer to a spot-market price, even though the spot market is often not the main balancing instrument for the TSO. The extent to which such a price is cost reflective for system balancing that is often based on just the use of line-pack flexibility remains a question. In our analysis of forum shopping for balancing rules, a reference market price (RMP expressed in EUR/ $\mathrm{m}^{3}$ ) is assumed for imbalances in each of the gas regions. ${ }^{6}$

Balancing-charge structures encompass three elements: cash outs, penalties and tolerances. Below, a distinction is made between, first, basic imbalance settlement that comprises of single-price methods in which the same price is used for either shipper imbalance position and dual-price methods that include a penalty term (see below in section 2.2.1) to be added to the cash-out fee, and, second, more complex incentive schemes that include multi-level penalties and tolerances (section 2.2.2). Finally, marketbased charges are discussed in section 2.2.3.

\subsubsection{Basic imbalance settlement: cash out (single price vs. dual price)}

End-of-balancing-period imbalances are financially settled through cash out: short shippers pay a fee to the TSO for the gas withdrawn from the system without having made a matching injection (withdrawal exceeds injection), whereas long shippers (injection exceeds withdrawal) receive a fee from the operator for injected gas surpassing offtakes over the period. The net balancing cost for a shipper is then obtained by taking into account the revenue $c_{1}$ for gas sold $\left(X_{D}\right)$ and the acquisition cost $c_{2}$ for produced/imported gas $\left(X_{S}\right)$ besides the fees $c_{3}$ and $c_{4}$ for long and short imbalances, respectively (Eq. (1)).

$$
\cos t=c_{1} \cdot X_{D}-c_{2} \cdot X_{S}+c_{3} \cdot\left(X_{S}-X_{D}\right)_{X_{S}-X_{D}>0}-c_{4} \cdot\left(X_{D}-X_{S}\right)_{X_{D}-X_{S}>0}
$$

Table 1 summarizes the most simple tariff structure for imbalance settlement. Long and short imbalances are cashed out at the same RMP independent of whether the shipper instigated the system imbalance or helped mitigate it.

\footnotetext{
${ }^{6}$ In this paper, prices are expressed in terms of euro per volume unit - the common unit for flows and imbalances. They are equivalent to prices expressed in euro per energy unit ( $\mathrm{kWh}$ or $\mathrm{MWh}$ ) using the caloric value (a typical value is $11 \mathrm{kWh} / \mathrm{m}^{3}$ ).
} 
Table 1: Tariff structure 1: basic settlement through cash-out fees (single price)

\begin{tabular}{llll}
\hline \hline $\begin{array}{l}\text { Tariff structure } 1 \\
{\left[\mathrm{EUR} / \mathrm{m}^{3}\right]}\end{array}$ & \multicolumn{2}{l}{ System imbalance } \\
& & Short & Long \\
\cline { 3 - 4 } Shipper & Short $^{\mathrm{a}}$ & RMP & RMP \\
imbalance & Long $^{\mathrm{b}}$ & RMP & RMP \\
\hline
\end{tabular}

${ }^{a}$ Shipper pays reference market price (RMP) per unit of imbalance to system operator

${ }^{\mathrm{b}}$ Shipper receives RMP from system operator

Tariff structure 1 succeeds in transferring financial responsibility for ex-post balancing services to shippers; although, actual balancing-cost reflectivity might be doubtful. But this simple cash-out structure entirely fails at providing additional incentives to balance ex ante because a shipper cannot do worse than by trading on the spot market if the RMP refers to that same spot market. ${ }^{7}$

Penalties make up the straightforward way of providing ex-ante balancing incentives to shippers. Penalties are non-cost reflective by their very nature. However, this potentially opens the door for revenue-generating penalties for the TSO while system balancing should not be a profitable business for the regulated TSO according to the industry literature on balancing (ACER, 2011; ERGEG, 2005, 2006, 2011).

Table 2 presents a cash-out system with added incentivizing penalties. Long shippers receive less than full RMP and short shippers pay more than just RMP. Penalties can be symmetrical ( $\alpha, \beta, \gamma$ and $\delta$ equal), or asymmetrical ( $\alpha, \beta, \gamma$ and $\delta$ different). In the latter case it is possible to differentiate the cash out according to the relative positions of the aggregated gas system and the individual shippers, allowing punishment of systemimbalance instigating shippers and rewarding shippers with mitigating positions.

Table 2: Tariff structure 2: cash out with added penalty (dual price)

\begin{tabular}{|c|c|c|c|}
\hline \multirow{2}{*}{\multicolumn{2}{|c|}{$\begin{array}{l}\text { Tariff structure } 2 \\
{\left[E U R / m^{3}\right]}\end{array}$}} & \multicolumn{2}{|c|}{ System imbalance } \\
\hline & & Short & Long \\
\hline Shipper & Short $^{\mathrm{a}}$ & $\mathrm{RMP} *(1+\alpha)$ & $\mathrm{RMP} *(1+\beta)$ \\
\hline imbalance & Long $^{\mathrm{b}}$ & $\mathrm{RMP} *(1-\gamma)$ & $\mathrm{RMP} *(1-\delta)$ \\
\hline
\end{tabular}

${ }^{a}$ Shipper pays charge per unit of imbalance to system operator

${ }^{\mathrm{b}}$ Shipper receives money for excess gas from system operator

\footnotetext{
${ }^{7}$ Note that the RMP could deviate from intra-day price levels, e.g., if RMP is defined as the average of intraday trades at different intra-day price levels.
} 
Differences in parameters $\alpha-\delta$ tempt shippers to arbitrate between different balancing mechanisms to minimize imbalance costs (see further).

\subsubsection{Complex incentive schemes: intra-period penalties and imbalance tolerances}

Balancing mechanisms with more complex incentive schemes go beyond just imbalance settlement. They impose penalties for unmatched positions inside the formal balancing interval, effectively reducing the actual balancing interval. Examples of such charges are penalties for hourly imbalances when the formal balancing period is a day or charges for the peak-cumulative imbalance within the formal interval.

Table 3: Tariff structure 3: intra-interval penalties and tolerances on top of basic settlement

\begin{tabular}{|c|c|c|c|}
\hline \multirow{2}{*}{\multicolumn{2}{|c|}{$\begin{array}{l}\text { Tariff structure } 3 \\
{\left[E U R / \mathrm{m}^{3}\right]}\end{array}$}} & \multicolumn{2}{|l|}{ System imbalance } \\
\hline & & Short & Long \\
\hline $\begin{array}{l}\text { Shipper intra- } \\
\text { period }\end{array}$ & Short & $\varepsilon * \mathrm{RMP} *(\mathrm{Imb}-\mathrm{Tol})$ & $\zeta * \operatorname{RMP} *(I m b-T o l)$ \\
\hline imbalance & Long & $\eta * \mathrm{RMP} *(\mathrm{Imb}-\mathrm{Tol})$ & $\theta * \mathrm{RMP} *(\mid \mathrm{mb}-\mathrm{Tol})$ \\
\hline
\end{tabular}

Tariff structure 3 (Table 3 ) shows penalties (with parameters $\varepsilon-\theta$ ) for intra-period imbalances (Imb) based on the RMP. These penalties are meant as additional balancing incentives and always involve payments to the system operator by the shipper complementing the settlement charges illustrated in tariff structure 2 . Note that even shippers who help the system by having an imbalance with the sign opposite to the system have to pay these penalties.

Still more complexity can be added to the tariff structure by means of granting penalty exemptions for some amount of tolerated imbalance (Tol). These tolerances actually reduce ex-ante balancing incentives as the penalties are now only imposed on the part of the imbalance beyond the tolerance level.

\subsubsection{Marginal-cost based settlement charges}

In the previous tariff structures, the RMP refers to a spot-market price - usually the dayahead price - that is not necessarily reflecting the marginal cost of flexible gas that is used to balance the system. If the TSO uses market-based procurement of balancing services and settlement of shipper imbalances, the imbalance tariff can be linked directly to the marginal price of dispatched flexibility by the TSO. The TSO, then, procures upward flexibility at marginal price $\mathrm{MP}_{\text {up }}$ if the system is short, and $\mathrm{MP}_{\text {down }}$ is the price of the 
marginal unit of dispatched downward flexibility if the system is long. This market-based settlement system succeeds in passing on the energy costs of flexibility to the users of that flexibility and provides signals to the market with regard to flexibility services. The Dutch bid ladder mechanism is an example of such market-based procurement. In this mechanism, market players place bids for offering upward/downward flexibility to be called by the TSO when the system requires intervention (GTS, 2012; WMWG, 2010).

Table 4: Tariff structure 4: market-based settlement through cash-out fees for short and long shipper positions

\begin{tabular}{|c|c|c|c|}
\hline \multicolumn{2}{|c|}{$\begin{array}{l}\text { Tariff structure } 4 \\
{\left[E U R / m^{3}\right]}\end{array}$} & \multicolumn{2}{|c|}{ System imbalance } \\
\hline Shipper & Short $^{a}$ & $\mathrm{MP}_{\text {up }}$ & $\mathrm{MP}_{\text {down }}$ \\
\hline imbalance & Long ${ }^{b}$ & $\mathrm{MP}_{\text {up }}$ & $\mathrm{MP}_{\text {down }}$ \\
\hline
\end{tabular}

The marginal cost in tariff structure 4 (Table 4) can be replaced with the average cost of procurement. In that case, however, the signaling function of the marginal price is lost.

The design of the balancing mechanism is basically a regulated decision, which implies that the balancing charges should be applied in a non-discriminatory manner for all

shippers. However, geographically distinct regions have their own rules, leaving opportunity for forum shopping. This is now illustrated through a case study, considering the UK and Belgium as two geographically adjacent, but distinctly regulated regions.

\section{Efficiency methodology}

The developed methodology calculates the efficiency gains of the shipper and the TSO when shippers apply a forum-shopping strategy (FS) compared to the benchmark autarkic strategy (AUT). In autarky, the shipper follows a national strategy excluding any movement of imbalances across borders. The forum-shopping strategy, on the other hand, concerns a cross-border optimization by the shipper, moving imbalances to the more lenient settlement mechanism. Both strategies assume nationally operated systems. Therefore, the respective TSOs can only rely on domestic sources of system flexibility. 


\subsection{Efficiency definitions}

Shippers engage into forum-shopping behavior if this is a profitable strategy. The efficiency surplus of the shipper in the combined region $\left(\Delta S_{\text {shipper,R1+R2 }}\right)$ is, therefore, defined as the difference between the profit applying the forum-shopping strategy and the profit using the autarkic strategy in the separate regions:

$$
\Delta S_{\text {shipper,R1+R2 }}=\left(\text { profit }_{F S, R 1}-\text { profit }_{A U T, R 1}\right)+\left(\text { profit }_{F S, R 2}-\text { profit }_{A U T, R 2}\right)
$$

Profit is defined as the revenues of selling gas minus the costs of importing gas and the imbalance costs and is calculated by GASFLEX, an operations research model of the shipper portfolio (Keyaerts, 2012b).

The TSO efficiency function $\left(\Delta S_{T S O, R 1+R 2}\right)$ in the combined region, then, is defined as the sum of the regional costs of balancing the system - calculated with GASFLEX, which also models the gas-network system - when shippers nominate according to the FS-strategy minus the balancing costs in the case that the shippers nominate according to the benchmark AUT-strategy:

$$
\Delta S_{T S O, R 1+R 2}=\left(\begin{array}{c}
\left(\text { balancingcost }_{F S, R 1}-\text { balancingcost }_{A U T, R 1}\right) \\
+\left(\text { balancingcost }_{F S, R 2}-\text { balancing } \operatorname{cost}_{A U T, R 2}\right)
\end{array}\right)
$$

Note that balancingcost are negative numbers, ensuring that positive surpluses correspond to efficiency gains for the TSO, who represents all gas-network users. Hence, a negative TSO surplus is a loss for the whole community of gas-market actors. The TSO surplus refers to costs only as the TSO-efficiency criterion since it is not the objective of the TSO to make a profit with his balancing activities.

To know the impact of forum shopping on the net welfare, thus the change in total efficiency in the combined region $\left(\Delta W_{R 1+R 2}\right)$, the total shipper-efficiency surplus and the total TSO-efficiency surplus have to be added:

$\Delta W_{R 1+R 2}=\Delta S_{\text {shipper }, R 1+R 2}+\Delta S_{T S O, R 1+R 2}$

\subsection{Gas-pipeline systems}

The comparative efficiency benchmarking requires the modeling of two distinct gas systems in geographically adjacent regions. Indeed, a physical interconnection must be present to allow forum shopping. Furthermore, a single shipper is assumed to be active in both regions. In other words, the shipper optimizes entry and exit nominations in the most profitable way accounting for the two sets of balancing rules. 


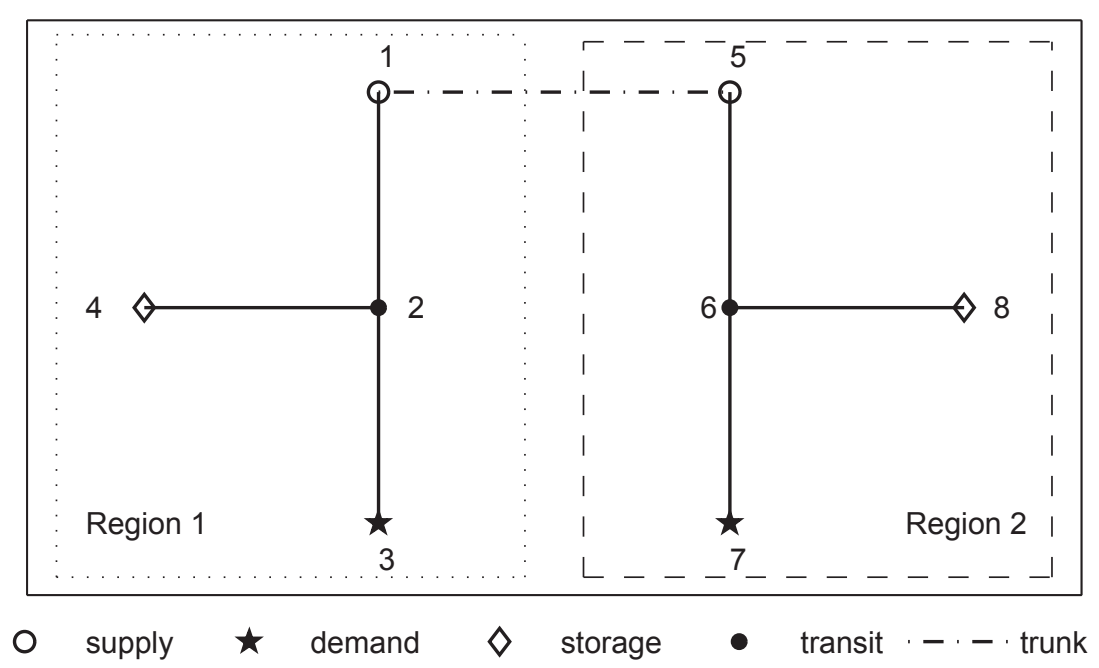

Fig. 2: Hypothetical gas-pipeline systems in two geographically adjacent and physically interconnected regions, region 1 equals nodes 1-4 and region 2 nodes 5-8, the networks consist of gas import nodes ( 1 and 5,0 ), gas demand nodes ( 3 and $7, \star)$, storage nodes $(4$ and 8,0$)$ and transit nodes $(2$ and $6, \bullet)$. Compressors are stationed in nodes 1 and 5. The physical interconnection (dash-dotted line) has to be interpreted as a big trunk line passing through nodes 1 and 5 from which both regions draw gas.

Fig. 2 plots the hypothetical gas networks in region 1 and region 2. Each gas system consists of an entry node (nodes 1 and 5) through which gas is imported. Next, gas is consumed downstream in nodes 3 and 7 . Besides pipeline storage, the systems each have an underground storage to provide flexible gas (nodes 4 and 8). The other nodes are just for transit, connecting multiple pipelines. The physical interconnection between the regions can be interpreted as a trunk line from which both regions draw gas, allowing the shipper to move imbalances by changing entry nominations in both regions. Finally, compressors are located in both entry nodes. Further technical details on the gas network are provided in an Appendix.

\subsection{Data and assumptions}

To isolate the effects of the settlement-mechanism design on the shipper behavior, exante flexibility is disregarded in the model. The effect of introducing ex-ante flexibility comes down to a decrease of ex-post imbalance costs at the cost of having to contract and deploy other flexibility like storage or flexible production. However, the focus in this paper is on the arbitrage possibilities between different sources of ex-post flexibility provided through the settlement mechanisms. 


\subsubsection{Gas demand}

Three generic demand profiles are considered: a) residential demand, b) electric power sector demand for GFPPs and c) industrial demand. The demand profiles are scaled to an average hourly demand of 1 million cubic meter per hour $\left(\mathrm{M} \mathrm{m}^{3} / \mathrm{h}\right)$ and cover two gas days, adding up to 48 hours, as illustrated in Fig. 3.
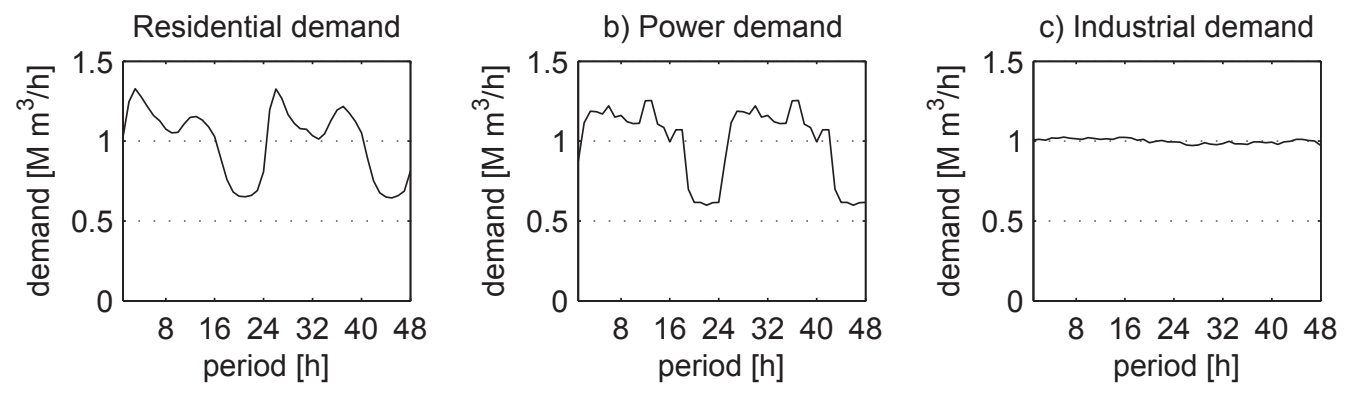

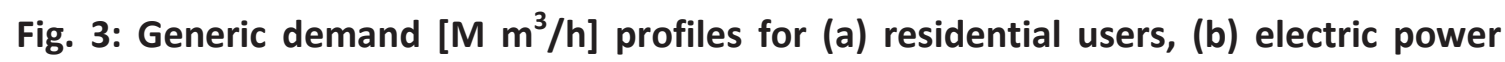
generation by GFPPs and (c) industry for two gas days; the average hourly demand has been scaled to $1 \mathrm{M} \mathrm{m}^{3} / \mathrm{h}$

\subsubsection{Gas supply}

The supply side is assumed to be rigid in both regions. Indeed, the shipper has a major import contract for both regions and just chooses where to move the gas to using his idle border and transport capacity rights. ${ }^{8}$ Furthermore, once an amount of gas is committed for a day, the amount cannot change. Re-nomination of gas between regions, on the other hand, is assumed possible. In fact, this re-nomination is the driver behind moving imbalances.

So, committed gas is entered $\left(\dot{V} b u y_{r, h}\right)$ in each region $r$ throughout the day based on forecasted demand for the respective regions. The effective demand $\left(\dot{V}_{s e} I_{r, h}\right)$ deviates from the forecasted demand according to a supposed forecast error. Because no ex-ante flexibility is considered, shippers rely completely on the ex-post-balancing mechanism for inevitable intra-day imbalances. In the absence of ex-ante flexibility, the daily portfolio imbalance in autarky comes down to the difference between the purchase contracts and the sales contracts for a region:

$\sum_{h} \dot{\operatorname{Vbuy}}{ }_{r, h}-\sum_{h} \dot{V}^{s e l l} r, h=\sum_{h} \dot{V i m b}_{r, h}$,

where $\dot{V i m b} b_{r, h}$ represents the hourly regional imbalance in the shipper portfolio.

\footnotetext{
${ }^{8}$ It is assumed that a transnational shipper books border capacity and transport capacity in all regions where he deploys his activities. Hence, capacity costs can be assumed to be sunk costs that are not further relevant for the analysis in this paper. If capacity utilization is full, marginal capacity costs become relevant again and provide a lower bound on the arbitrage surplus needed for forum shopping to be profitable.
} 
When shippers pursue a forum-shopping strategy, Eq. (5) is replaced by Eq. (6). In that equation, cross-border movement $\left(M_{r, h}\right.$ expressed in $\mathrm{M} \mathrm{m}^{3} / \mathrm{h}$ and positive for import into region $r$ ) is added to represent the possibility of imbalance-trade. ${ }^{9}$

$\sum_{h} \dot{V}$ buy $r, h-\sum_{h} \dot{V}_{S e l l}, h=\sum_{h} \dot{V i m b}_{r, h}-\sum_{h} M_{r, h}$

11 forecast errors (FE) are applied on the generic demand profiles for each of the three demand types (Fig. 3), resulting in $33(3 \times 11)$ supply profiles ranging from underestimating demand at 85 percent, so 15 percent short, over perfect forecasting to overestimating demand at 115 percent, meaning 15 percent of surplus gas is injected in the system on a daily basis. ${ }^{10}$ These profiles cover the range of relevant situations with short and long positions for different types of demand.

\subsubsection{Settlement mechanism}

Different settlement-mechanism designs are the main driver for forum shopping. As a case study, the settlement mechanisms of Belgium and the United Kingdom are studied. These mechanisms serve as excellent illustrations of the different settlement-design options. Moreover, these two gas systems are effectively adjacent and connected by a physical infrastructure, making forum shopping a real possibility.

The UK applies daily imbalance settlement with a double-price mechanism. Indeed, the UK's TSO uses a different spot-market-based price (APX ENDEX, 2012) for buying gas from shippers facing long positions and selling gas to shippers facing short positions. The spread between the system marginal prices for buying $\left(\mathrm{SMP}_{\text {buy }}\right)$ and selling $\left(\mathrm{SMP}_{\text {sell }}\right)$ gas compared to the average price constitutes an implicit penalty for unbalanced shippers. ${ }^{11}$ Furthermore, the TSO does neither impose fees for intra-day imbalances, nor are any tolerances granted. Details of the UK balancing mechanism can be found in the UK's network code (Joint Office of Gas Transporters, 2013; National Grid, 2012a).

Mathematical imbalances $\left(\mathrm{M} \mathrm{m}^{3}\right)$, meaning the mathematical difference between gas entered $\left(\dot{V} b u y_{r, h}\right)$ and gas withdrawn $\left(\dot{V}_{s e} I_{r, h}\right)$ over a period $h$ in region $r$, are transformed into economic imbalances $\left(\mathrm{M} \mathrm{m}^{3}\right)$. These transformations are made for modeling reasons and they account for nominations, applicable tolerances and penalties. The imbalance fee

\footnotetext{
${ }^{9}$ The straightforward interpretation of this "movement" is the re-nomination of entry in the respective regions. This re-nomination is then facilitated by the availability of better information closer to real time, allowing the shippers to estimate their imbalances.

${ }^{10}$ The superimposed forecast errors on the daily demand range from $-15 \%$ to $+15 \%$ in steps of 3 percentage points: $-15 \%,-12 \%,-9 \%,-6 \%,-3 \%, 0 \%,+3 \%,+6 \%,+9 \%,+12 \%,+15 \%$.

${ }^{11}$ The definitions of the system marginal prices can be simplified to: the "SMP buy" is the highest price paid for a balancing action for the day; whereas the "SMP sell" is the lowest price offered for a balancing action for the day (Joint Office of Gas Transporters, 2013).
} 
in euro is then obtained by multiplying the different economic imbalances with the applicable reference price(s). Thus, it is the economic imbalance that serves as a corrected basis for levying imbalance charges.

Table 5 summarizes the transformations for the UK. Mathematical hourly and cumulativehourly imbalances are transformed to 0 and, therefore, do not give rise to any penalty charges. With regard to the end-of-day imbalance, a distinction is made - for modeling reasons - between the (possible) imbalance penalty and the cash out. The UK settlement mechanism does not impose an explicit daily penalty; so, the end-of-day imbalance is in that case transformed into an economic imbalance of 0 . For the cash out, on the other hand, the shipper is accountable for his full mathematical imbalance. Hence, the economic imbalance for daily cash out is the same as the shipper's mathematical imbalance. For short shippers, then, the applicable reference price is the $\mathrm{SMP}_{\text {buy }}$ and for long shippers the $\mathrm{SMP}_{\text {sell}}$.

Table 5: UK - transformation of a shipper's mathematical imbalances (nominations) into economic imbalances (nominations, tolerances and penalty part) that serves as a basis to charge balancing fees

\begin{tabular}{lll}
\hline \hline UK & Mathematical imbalance $\left[\mathrm{M} \mathrm{m}^{3}\right]$ & Economic imbalance $\left[\mathrm{M} \mathrm{m}^{3}\right]$ \\
\hline transformations & $\dot{V} b u y_{h}-\dot{V} s e I_{h}$ & 0 \\
Cumuly penalty & $\forall h: \sum_{h}\left(\dot{V} b u y_{h}-\dot{V} s e I_{h}\right)$ & 0 \\
Daily penalty & $\sum_{h}\left(\dot{V} b u y_{h}-\dot{V} s e I_{h}\right)$ & 0 \\
Cash out (daily) & $\sum_{h}\left(\dot{V} b u y_{h}-\dot{V} s e I_{h}\right)$ & $\sum_{h}\left(\dot{V} b u y_{h}-\dot{V} s e l I_{h}\right)$ \\
\hline \hline
\end{tabular}

Belgium, on the other hand, has a much more complex balancing mechanism as demonstrated by Table 6 (Fluxys, 2010, 2011, 2012). ${ }^{12}$ The formal balancing interval is one day, but hourly short positions are also penalized, and the peak cumulative imbalances within the day give also rise to an imbalance charge. Furthermore, shippers receive tolerances pro rata of their booked transport capacity and penalties are further charged according to a stepwise-linear function for long and short shipper positions.

\footnotetext{
${ }^{12}$ By late 2012, the Belgian TSO has been introducing balancing-mechanism reforms to make the balancing rules more market based. While the balancing period remains formally a day, within-day settlement of cumulative imbalance positions is now possible when the system imbalances demands TSO intervention. In that case, the TSO buys/sells gas on a market platform to mitigate the system imbalance, charging the costs to the causers of the within-day imbalance. This new balancing rules could be included in follow-up research.
} 
Table 6: Belgium - transformation of mathematical imbalances (nominations) into economic imbalances (nominations, tolerances and penalty part) that serve as basis to charge balancing fees

\begin{tabular}{|c|c|c|}
\hline $\begin{array}{l}\text { Belgian } \\
\text { transformations }\end{array}$ & Mathematical imbalance $\left[\mathrm{M} \mathrm{m}^{3}\right]$ & Economic imbalance $\left[\mathrm{M} \mathrm{m}^{3}\right]$ \\
\hline \multirow[t]{2}{*}{ Hourly penalty } & \multirow[t]{2}{*}{$\dot{V} b u y_{h}-\dot{V}_{s e l l}$} & Long: 0 \\
\hline & & Short: $\dot{V} b u y_{h}-\dot{V}_{s e l l}-T o l-H$ \\
\hline \multirow{7}{*}{$\begin{array}{l}\text { Cumulative hourly } \\
\text { penalty }\end{array}$} & \multirow{7}{*}{$\operatorname{Max}\left(\forall h: \sum_{h}\left(\dot{V} b u y_{h}-\dot{V} s e I_{h}\right)\right)$} & $0 \rightarrow$ Tol-CH: 0 \\
\hline & & Tol-CH $\rightarrow 2$ Tol-CH: \\
\hline & & $0.4 \sum_{h}\left(\dot{V} b u y_{h}-\dot{V}_{s e l l}-T o l-C H\right)$ \\
\hline & & $2 \mathrm{Tol}-\mathrm{CH} \rightarrow 3 \mathrm{Tol}-\mathrm{CH}:$ \\
\hline & & $0.6 \sum_{h}\left(\dot{V} b u y_{h}-\dot{V}_{s e l} l_{h}-2 T o l-C H\right)$ \\
\hline & & $3 \mathrm{Tol}-\mathrm{CH} \rightarrow \ldots:$ \\
\hline & & $0.8 \sum_{h}\left(\dot{V} b u y_{h}-\dot{V}_{s e l l}-3 T o l-C H\right)$ \\
\hline \multirow[t]{7}{*}{ Daily penalty } & \multirow{7}{*}{$\sum_{h}\left(\dot{V} b u y_{h}-\dot{V} s e l l_{h}\right)$} & $0 \rightarrow$ Tol-D: 0 \\
\hline & & Tol-D $\rightarrow$ 2Tol-D: \\
\hline & & $0.4 \sum_{h}\left(\dot{V} b u y_{h}-\dot{V} s e I_{h}-T o l-D\right)$ \\
\hline & & 2Tol-D $\rightarrow$ 3Tol-D: \\
\hline & & $0.6 \sum_{h}\left(\dot{V} b u y_{h}-\dot{V}_{s e l} l_{h}-2 T o l-D\right)$ \\
\hline & & $3 T o l-D \rightarrow \ldots:$ \\
\hline & & $0.8 \sum_{h}\left(\dot{V} b u y_{h}-\dot{V}_{s e l l}-3 T o l-D\right)$ \\
\hline Cash out (daily) & $\sum_{h}\left(\dot{V}_{b u y_{h}}-\dot{V} s e I_{h}\right)$ & $\sum_{h}\left(\dot{V} b u y_{h}-\dot{V} s e l I_{h}\right)$ \\
\hline
\end{tabular}

Note 1: transformations are symmetrical if no distinction is made between short and long Note 2: tolerances are symmetrical, but of opposite sign for short and long positions Note 3: $\max$ becomes $\min$ for negative cumulative imbalance

For instance, a penalty of 0 is applied for imbalances within the limits of the daily tolerance $(T o l-D), 40$ percent of the reference price is due for the part of the imbalance between Tol-D and two times Tol-D, 60 percent between twice Tol-D and triple Tol-D, and, finally, 80 percent beyond three times the daily tolerance level. The cumulative penalties, which are due for the peak positive and peak negative cumulative imbalances, are determined in a similar way. The cash out of the end-of-day imbalance in Belgium uses the full imbalance as a settlement basis as shown in the last row of Table 6. In the case of hourly imbalances, only gas deficits beyond the hourly tolerance level $(\mathrm{Tol}-H)$ give rise to penalties, whereas hourly gas surpluses are transformed to 0 .

The Belgian settlement mechanism uses a basket of prices rather than a single market price to establish an RMP. Interestingly, in addition to the DJ Zeebrugge Index Gas (ZIG) 
this basket includes the $\mathrm{SMP}_{\text {buy }}$ (short) and $\mathrm{SMP}_{\text {sell }}$ (long) prices that are also applicable in the UK.

As far as price data are concerned, the intra-day $\mathrm{SMP}_{\text {buy }}$ and $\mathrm{SMP}_{\text {sell }}$ are used for the UK (APX ENDEX, 2012; National Grid, 2012b), whereas the ZIG (Thomson Reuters, 2011) is applied for Belgium. ${ }^{13}$ Additionally, other price scenarios, calibrated on historic data of the price indices mentioned above, have been examined to show that it is the settlement design rather than diverging market prices in different regions that incentivize shippers to do forum shopping. Cross-border trade that is the result of price differences is a relevant topic, but is not part of the present study.

\section{Results of forum shopping on the UK-Belgian gas border}

\subsection{Shipper surplus}

Fig. 4 shows the net shipper costs for acquiring ex-post-balancing services from the TSOs in the benchmark case (AUT) and the forum-shopping case (FS). Note that the results are ordered on the horizontal axis according to the forecast error (FE): underestimating demand with 15 percent means that the shipper has an end-of-day deficit of 15 percent in the combined region because too few gas has been committed.

a) Residential

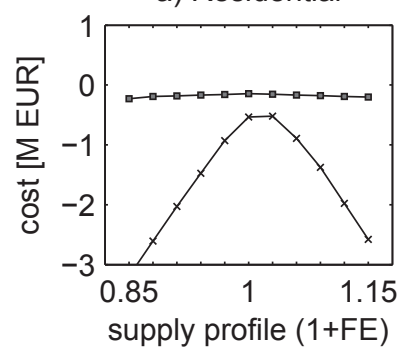

b) Power

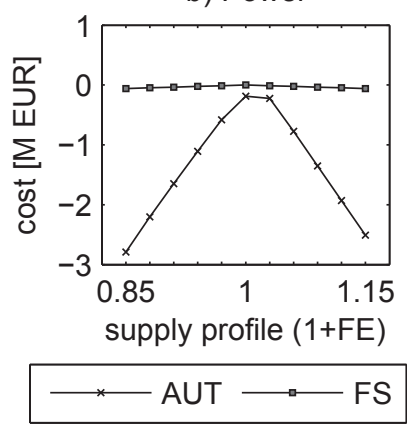

c) Industrial

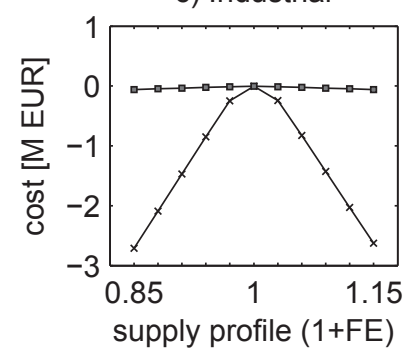

Fig. 4: Shipper imbalance costs (million euro) in the combined region (BE+UK) for the benchmark case (AUT) and the cross-border case (FS) and for a) residential demand, b) power sector demand and $\mathrm{c}$ ) industrial demand; the supply profiles are ranked according to their respective forecast error (FE)

In autarky, the combined costs in the Belgian and UK regions are much larger and have a stronger dependency on the forecast error. The costs in the forum-shopping case, on the other hand, are much smaller and less dependent on the forecast error. These

\footnotetext{
${ }^{13}$ Price levels have been calibrated with historic data to obtain reasonable price estimates. The exact price levels, however, are not important in the context of the current work.
} 
observations are explained by the settlement-design differences between the two regions that have been established by Table 5 for the UK and Table 6 for Belgium. In autarky, the dominant Belgian settlement costs determine to a large extent the shipper's costs for expost flexibility. By trading imbalances to the UK in the FS-case (see further), the costs are predominantly determined by the more lenient UK settlement design. If the separate autarkic imbalance costs of the Belgian and the UK region would have been plotted, the AUT line would almost coincide with the Belgian autarkic settlement costs and the FS line would resemble more or less the autarkic UK costs. Comparing the three panels, the residential-demand profiles return slightly higher settlement costs due to the presence of larger intra-day variation than for the assumed power-sector and industrial-sector profiles. Nevertheless, the demand type seems to have little effect on the costs in the examined cases because we presuppose forecast errors. A flatter demand of the industrial type is likely easier to be forecasted, thus lowering the forecast error and thus the imbalance costs, independent of the autarkic or forum-shopping strategy, but forum shopping could still generate a profit by further reducing that small cost.

For all investigated scenarios, forum shopping proves to be a profitable strategy for a shipper, as illustrated in Fig. 5. Indeed, moving imbalances between regions saves money for the transnational shipper as ex-post flexibility becomes less costly. Clearly, the absolute shipper surplus (left-hand side of Fig. 5) is dependent on the quality of the demand forecast as for good-quality forecasts (middle profiles) the surplus is much lower than for the cases in which demand is much more underestimated (left-hand side) or overestimated (right-hand side). This observation suggests that shippers have no incentive to improve demand forecasts as long as they can transfer imbalances to a balancing mechanism that is lenient for intra-day imbalances. Indeed, shippers will only invest in forecasting, or ex-ante flexibility, if the reduced costs by avoided imbalances in the cheapest settlement mechanism exceed the costs of better forecasting or contracting flexibility. Furthermore, the left-hand side panel of Fig. 5 shows that absolute shipper surpluses are slightly higher for demand types that have more intra-day variation, especially when demand has been underestimated (negative forecast error). The asymmetry in the Belgian imbalance charges regarding hourly imbalances explains why a similar outcome for overestimated demand is not observed. Indeed, hourly shortages are subject to a penalty, whereas hourly surplus positions are not (Table 6). 
a) Absolute efficiency change

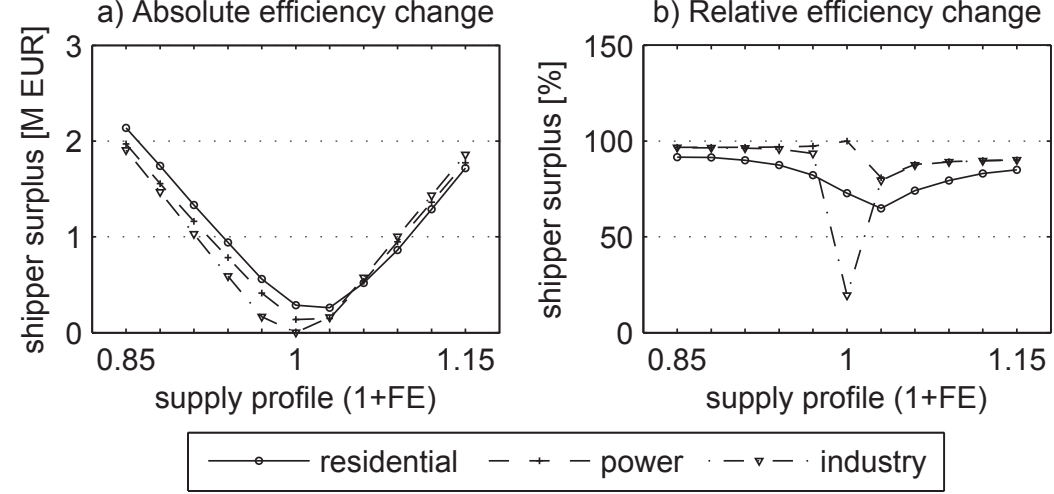

Fig. 5: (a) absolute and (b) relative shipper surplus by forum shopping (FS) for balancing rules compared to separate balancing in the UK and Belgium (AUT) for 3 characteristic demand profiles and 11 supply profiles $(1+\mathrm{FE})$ that are based on assumed demand forecast errors (FE)

The right-hand side panel of Fig. 5 shows that the shipper profit changes are also substantial in relative terms comparing the shipper-imbalance cost reductions with the benchmark costs in autarky. An asymmetry is observed between the supply profiles that underestimate demand and those that overestimate demand with the former resulting in slightly higher relative reductions compared to the latter. As before, this is explained by asymmetries in the settlement designs. Furthermore, differences can be observed between the different customer profiles with the residential demand profile having lower relative-surplus potential than the other demand types, which have almost overlap. This is due to the intra-day variation: residential demand is subject to higher costs in absolute terms for autarky as well as for forum shopping. Hence, the denominator in the relative surplus is a higher cost than for the other demand types.

Looking at the direction of gas movement in Fig. 6, gas is exported from the UK to Belgium when demand is underestimated, on the one hand; and the UK imports gas from Belgium when demand is overestimated, on the other hand. Both movements correspond to reducing the exposure of the shipper to the more penalizing Belgian balancing mechanism. Indeed, if demand is substantially underestimated, the shipper is likely to be in a short position in both gas systems. However, by exporting gas from the UK to Belgium, the shipper increases exposure to the UK balancing mechanism by further shorting, whereas the imported gas decreases the open imbalance position in Belgium. Imports do not differ much between demand types; hence, the almost overlapping lines in Fig. 6. 


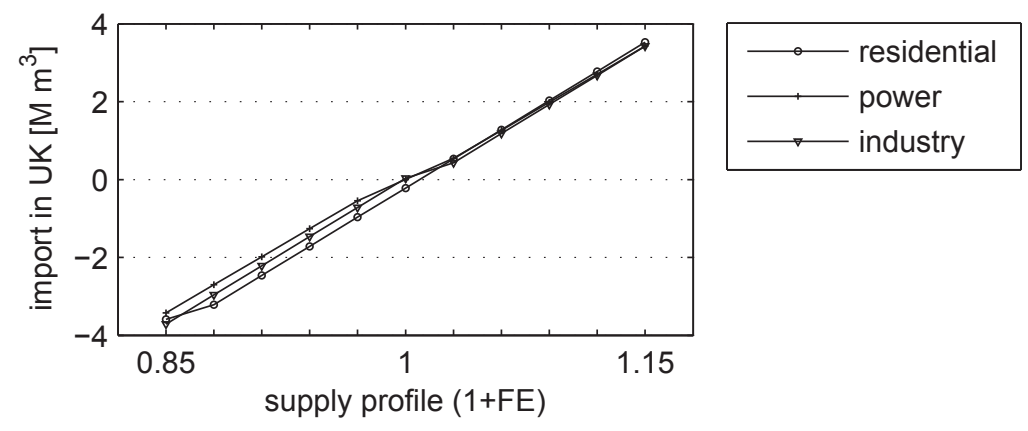

Fig. 6: Imbalance trade: import $(>0)$ of gas in the UK from Belgium or export $(<0)$ from the UK to Belgium - 11 supply profiles (1+FE) based on assumed demand forecast errors (FE); surplus gas in Belgium is exported to the UK, if the shipper is short in both regions, gas is exported from the UK to Belgium to reduce exposure to the penalizing settlement-mechanism

Fig. 7 shows a similar analysis for a range of RMPs for the UK and Belgian regions and for residential demand.

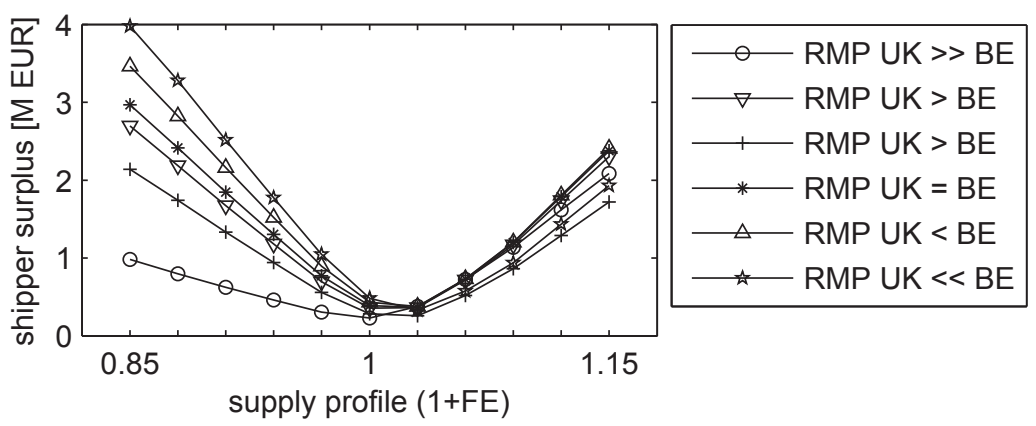

Fig. 7: Shipper surplus (residential-demand case) by forum shopping (FS) compared to an autarkic strategy (AUT) for 11 supply profiles based on assumed demand forecast errors (FE) and for different values of the respective RMPs in both regions: short positions offer bigger profits than long positions because of the asymmetry in the Belgian settlement mechanism regarding hourly imbalances; the more the UK RMP exceeds the Belgian RMP, the lower the surplus for short positions (negative FE), and that same surplus increases the more the Belgian RMP exceeds the UK RMP; a similar trend is not observed for positive $\mathrm{FE}$

The shipper surplus again rises with increasing forecast errors, meaning that total imbalance costs in the combined regions are reduced by moving imbalances compared to those costs in an autarkic strategy. Long positions provide less profit opportunities 
because of the asymmetry in the Belgian settlement mechanism which only penalizes hourly short positions. For the short imbalances (negative forecast error) the range of outcomes is dependent on the difference between the UK RMP and the Belgian RMP. The more the Belgian RMP exceeds the UK RMP, the higher the potential surplus becomes. If the UK RMP, on the other hand, exceeds the Belgian RMP, the surpluses are smaller. A similar trend cannot be observed for positive forecast errors. Indeed, the surplus remains fairly stable for the different RMP cases. Furthermore, the absolute profit opportunities are dependent on the absolute level of the Belgian RMP because the penalties are directly related to that price. Hence, the low surplus for negative forecasts is explained by the Belgian RMP being much lower than the UK RMP (RMP UK >> BE in Fig. 7), but also by the low absolute value that was considered in that particular case.

The results presented above suppose that the shipper can access an unlimited amount of ex-post-balancing services in each region. However, trade restrictions, like border capacity, limit the accessibility of cross-border services. In that case, the surpluses remain positive, but are topped off for big forecast errors because the shipper can only move imbalances up to a pre-determined level that is lower than the optimal level of imbalance trades. Five different border capacities, listed in Table 7, have been considered. It should be noted that the largest considered capacity in Table 7 amounts to 15 percent of the scaled average hourly demand and it will be shown below that this capacity is not binding and thus corresponds to the unrestricted case that has been discussed above.

Table 7: Considered border capacities $\left[\mathrm{M} \mathrm{m}^{3} / \mathrm{h}\right.$ ] for trade between the regions

\begin{tabular}{|c|c|c|c|c|}
\hline $\begin{array}{l}\text { Capacity } 1 \\
{\left[\mathrm{M} \mathrm{m}^{3} / \mathrm{h}\right]}\end{array}$ & $\begin{array}{l}\text { Capacity } 2 \\
{\left[\mathrm{M} \mathrm{m}^{3} / \mathrm{h}\right]}\end{array}$ & $\begin{array}{l}\text { Capacity } 3 \\
{\left[\mathrm{M} \mathrm{m}^{3} / \mathrm{h}\right]}\end{array}$ & $\begin{array}{l}\text { Capacity } 4 \\
{\left[\mathrm{M} \mathrm{m}^{3} / \mathrm{h}\right]}\end{array}$ & $\begin{array}{l}\text { Capacity } 5 \\
{\left[\mathrm{M} \mathrm{m}^{3} / \mathrm{h}\right]}\end{array}$ \\
\hline 0.03 & 0.06 & 0.09 & 0.12 & 0.15 \\
\hline
\end{tabular}

Fig. 8 shows the shipper surplus for the different levels of trade capacity from Table 7 ( $y$ axis). Only the generic residential demand is considered here, but the results for the electricity-sector and industry-sector demand are similar. The more restricted the trade opportunities, the lower the actual surplus that can be captured by the transnational shipper. The trade restrictions become only relevant if there is a substantial positive or negative forecast error. Otherwise, there is no advantage for the shipper to move imbalances across borders. This is shown in Fig. 8 by the flat zone for supply profiles that have a forecast error close to zero. 


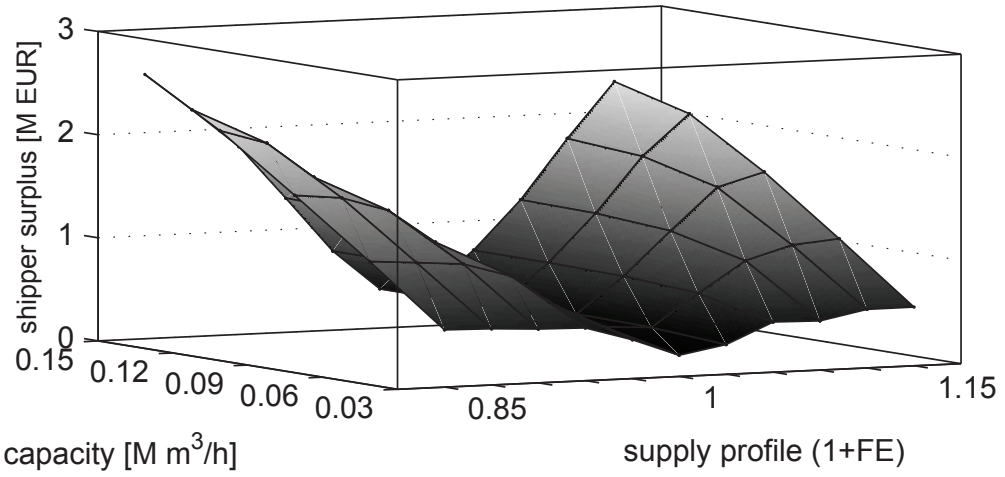

Fig. 8: Shipper surplus FS compared to AUT (residential-demand case) - Imbalance trade limited by border capacity - $x$-axis: 11 supply profiles $(1+F E)$ based on forecast errors

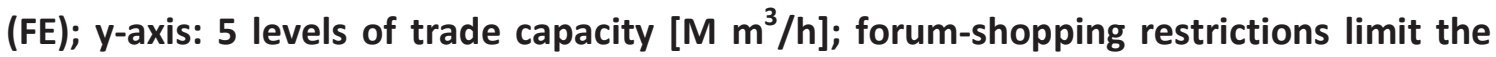
surplus that can be captured by the shipper

Fig. 9, then, shows the import of imbalances into the UK region for different tradecapacity levels. Positive numbers indicate the import of gas into the UK, whereas negative numbers correspond to export of gas (equivalent to importing a deficit) from the UK to Belgium.

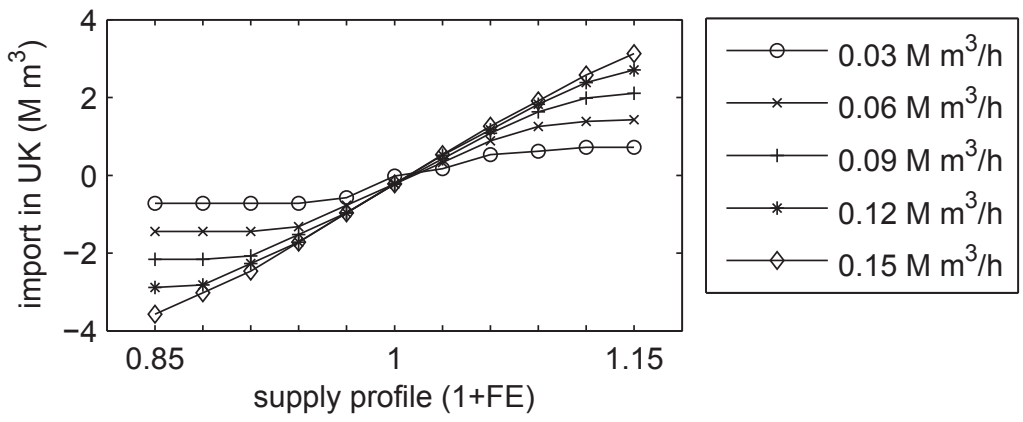

Fig. 9: Imbalance trade (residential-demand case): import $(>0)$ of gas in the UK from Belgium or export $(<0)$ from the UK to Belgium - Limited ex-post-balancing services offered by TSO - for 11 supply profiles (1+FE) based on assumed demand forecast errors (FE) and different levels of trade restrictions - the more restricted forum shopping becomes, the more imbalance exchange deviates from the optimal level without any restrictions 
The diamond markers represent the optimal trade strategies for the different forecast errors if there is no binding restriction on trade. The more restricted the trade opportunities become, the more actual trade deviates from those optimal levels.

Repeating the analysis for lower and higher daily demand, both by scaling and by adding a constant demand, returned similar results to the ones presented here. Therefore, shippers gain from shopping for balancing rules and arbitrating between a lenient mechanism with reference to intra-day imbalances (UK), and a more penalizing mechanism (Belgium). So, adapting intra-day nominations to move imbalances to the less-costly settlement mechanism is a profitable strategy for the shipper. In fact, the shipper cannot do worse than the autarky strategy, since that strategy remains available. The shipper could lose on a wrongfully pursued forum-shopping strategy if he is not a price taker. Indeed, if the movement of imbalances affects the imbalance tariff in one region or in both, the shipper profit could reduce. This could happen, for instance, if dumping surplus gas in the UK system results in a lower market value of the shipper's gas in the UK region.

\subsection{TSO surplus}

The TSOs face the system imbalances caused by the shipper in their respective region. To accommodate the imbalance in his region, a TSO can rely on domestic flexibility sources: line-pack flexibility and conventional storage. The operational cost of line-pack flexibility comes down to compression costs to control the pressure in the system and the valuation of the line-pack change. In reality, operational line-pack costs are negligible compared to the capacity cost of pipeline storage, but the amount of gas stored in a pipeline affects the required pressure levels to keep the system running (Eberhard and Hüning, 1990). Hence, when compression occurs in the local gas network, the compressor's fuel cost serves as an operational cost for pipeline flexibility. If no local compression is available or required, on the other hand, pipeline flexibility comes at no operational cost. Indeed, the responsibility to provide adequate pressure at the entry node lies outside the local gas system in such cases. Note that compressors offer a bundled service of transport and flexibility and that, in practice, the fuel cost of the compressor cannot be attributed entirely to the balancing of the system. Any attempt to disentangle that mixed use has been disregarded here to simplify the analysis and thus all costs are attributed here to balancing.

Operational storage costs have been considered for injection and withdrawal. Because of the short-term horizon of the analysis, capacity costs for, e.g., compression and storage are disregarded. Table 8 lists exemplary cost parameters for the efficient region and the expensive region. The cost parameters are hypothetical, but the orders of magnitude 
have been derived from bid-ladder data published by the Dutch TSO (GTS, 2012). Compression costs, then, are approximated by the cost of fuel gas.

Table 8: Operational costs [EUR/ $\mathrm{m}^{3}$ ] for storage and compression in the efficient and expensive regions, respectively (sample values inspired by actual bid-ladder data (GTS, 2012))

Efficient region cost $\left[E U R / \mathrm{m}^{3}\right] \quad$ Expensive region cost $\left[\mathrm{EUR} / \mathrm{m}^{3}\right]$

\begin{tabular}{lll}
\cline { 2 - 3 } \begin{tabular}{l} 
Storage injection \\
\cline { 2 - 3 } (downward flexibility)
\end{tabular} & 0.02 & 0.06 \\
$\begin{array}{l}\text { Storage withdrawal } \\
\text { (upward flexibility) }\end{array}$ & 0.02 & \\
Compression cost & 0.12 & 0.06 \\
\hline
\end{tabular}

The effects of increasing cost-efficiency differences between the regions, then, are investigated with four relative-efficiency (RE) scenarios (Table 9).

Table 9: Relative efficiency (RE) scenarios: expensive region costs for storage services (efficient region costs are kept constant to the levels provided in Table 8)

\begin{tabular}{lllll}
\hline \multirow{2}{*}{ Storage injection } & $\mathrm{RE} 1\left[\mathrm{EUR} / \mathrm{m}^{3}\right]$ & $\mathrm{RE} 2\left[\mathrm{EUR} / \mathrm{m}^{3}\right]$ & $\mathrm{RE3}\left[\mathrm{EUR} / \mathrm{m}^{3}\right]$ & $\mathrm{RE4}\left[\mathrm{EUR} / \mathrm{m}^{3}\right]$ \\
\cline { 2 - 5 } Storage withdrawal & 0.06 & 0.18 & 0.30 & 0.42 \\
\hline \hline
\end{tabular}

Two mutually exclusive situations can occur. Either the settlement mechanisms are designed in line with the effective balancing costs in the respective regions (right incentive) or the settlement mechanisms provide wrong incentives. A right incentive is provided if the more lenient settlement mechanism has the most efficient tools for balancing. If the lenient settlement mechanism relies on the more expensive balancing instruments, a wrong incentive is provided to the shippers. The previous subsection has demonstrated that shippers prefer the lenient UK settlement mechanism over the Belgian design. Therefore, the right-incentive case supposes that the UK is the efficient region. In the wrong-incentive case, on the other hand, the Belgian TSO is the more efficient region to balance the gas system.

Fig. 10 shows the TSO surpluses for the combined UK and Belgium regions for the residential-demand profiles. The left-hand panel plots the results for the right-incentive case (UK more efficient balancing region) and the right-hand panel shows the wrongincentive case (UK less efficient balancing region). 
a) Right incentive

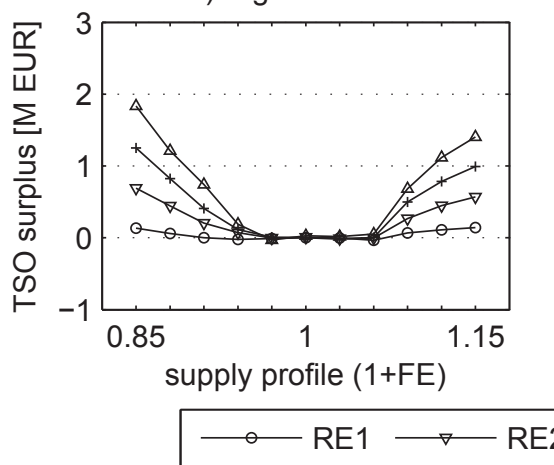

b) Wrong incentive

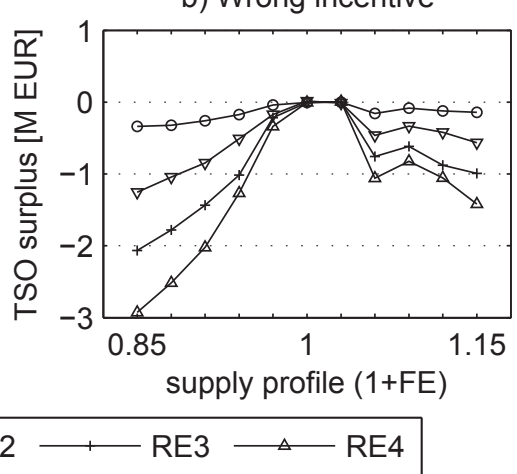

Fig. 10: TSO surplus [M EUR] (Residential-demand case)- a) lenient settlement region has more efficient balancing instruments and b) lenient settlement region has more expensive balancing instruments - for 11 supply profiles based on assumed demand forecast errors (FE) and 4 relative-efficiency (RE) scenarios: surpluses become more extreme if ex-post-balancing needs increase (larger forecast errors) and if the expensive region becomes more inefficient (RE1 >> RE4)

The TSO surplus is never negative if the correct incentive is provided, and the more extreme imbalances become, the more efficiency gains can be captured. The latter is only true to the extent that the UK has an absolute cost advantage, meaning it is the more efficient region to balance independent of the amount of flexible gas that is dispatched. In practice, it can be expected that a hypothetical merit order of all available flexibility in the combined region mixes the regionally available flexibility. ${ }^{14}$ Indeed, the first three flexibility instruments in the UK might be cheaper than in Belgium, but the next most efficient source might be located in Belgium followed by another UK source and so on. If the wrong incentive is provided by the relative settlement mechanisms, the TSO surplus is negative and the efficiency of the combined TSOs is reduced (Fig. 10.b). Indeed, imbalances are moved by shippers to regions that are less efficient in handling these imbalances. Hence, the demand for ex-post-balancing services rises in the expensive region because shippers profit from the lower settlement charges.

Finally, in Fig. 10, the outcome of the surpluses in absolute terms clearly depends on the relative efficiency $(\mathrm{RE})$ of the regions. Therefore, the relative efficiency is identified as the major determinant for the TSO efficiency if the shipper nominations have been fixed.

\subsection{Net surplus: TSO surplus + shipper surplus}

The net efficiency gain of the combined region depends on both the shipper surplus and the TSO surplus. Hence, both surpluses are to be accounted for to evaluate the impact of

\footnotetext{
${ }^{14}$ The combined merit order is hypothetical because procurement of flexibility is assumed a domestic issue.
} 
forum shopping on overall efficiency. In absolute terms, the TSO-efficiency change is of the same order of magnitude as the shipper surplus. Hence, if the TSO surplus is negative, the net surplus can also become negative. The actual outcome is dependent on the relative efficiency of the regions. Indeed, if the flexibility-cost difference increases between the efficient and the expensive region, the net result can become negative. If the relative efficiencies are small, on the other hand, the TSO surplus can still be negative, but overall efficiency will increase.

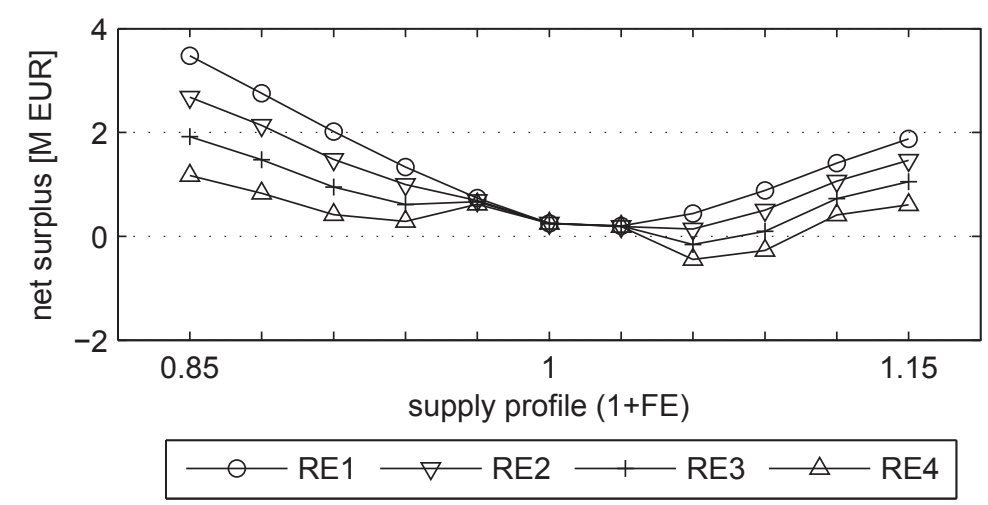

Fig. 11: Net surplus [M EUR] for the wrong-incentives case (residential-demand profiles for unrestricted border capacity): imbalances are moved to the less efficient region to balance, lowering net efficiency of the TSOs and the shippers in the combined region for 11 supply profiles based on demand-forecast error (FE) and 4 different relative efficiencies (RE) - if relative efficiency decreases (spread between efficient and expensive region increases) negative net surpluses are possible

In Fig. 11, it is demonstrated that the outcome for the wrong-incentive case and assuming no border restrictions, indeed, can become negative, reducing total efficiency. Further increasing the flexibility-cost difference would result in more occurrences of negative net surpluses for positive and, then, also negative forecast errors.

\section{Summary and conclusions}

This paper has demonstrated that balancing is no longer an isolated activity in a balancing area in a liberalized gas market encompassing several countries or regions. On the contrary, profit-maximizing transnational shippers can reduce their exposure to ex-post imbalance-settlement fees by "forum shopping" for the best balancing mechanism across borders.

The different designs of, e.g., the UK and Belgian settlement mechanisms provide an incentive for shippers to "move" imbalances as much as possible to the more lenient UK. 
Indeed, both regions have a completely different approach towards intra-day imbalances: in the UK, coverage of intra-day imbalances is free, whereas in Belgium, these imbalances are subject to penalty charges. Other borders between adjacent gas regions provide similar opportunities for transnational shippers, e.g., France and Belgium, Austria and any neighbor with daily balancing. Computational work for other borders can be considered for extending the ideas developed in this paper.

Using a "welfare"-benchmarking methodology, the impact on efficiency of moving from autarkic strategies to forum-shopping strategies has been demonstrated for the transnational shippers and the national TSOs. The shipper surplus is positive for all investigated cases, independent of the kind of customers the shipper serves. Because shippers can do this imbalance "trading" intra-day, they can only gain from forum shopping. Indeed, they can always revert to their original autarkic strategy. However, trade restrictions, e.g., insufficient border-capacity rights, limit the profits that can be captured by the shippers. The TSO surplus, on the other hand, is not indisputably positive. If the regional settlement mechanisms give wrong incentives, the combined TSOs see a loss in efficiency caused by the import of imbalances in the more expensive region to balance. Shippers only see the settlement mechanism and do not care for the effective balancing costs in non-market-based-settlement designs. Furthermore, if the relative efficiency of the expensive region compared to the efficient region decreases, the TSO surplus becomes more outspoken. If the right incentive is given, more efficiency gains are achieved, but if the wrong incentive is provided, the operator loss inflates. Net efficiency, then depends on the sum of TSO surplus and shipper surplus. If the system-balancing costs are lower for the forum-shopping strategy compared to the system costs for the autarkic strategy, the TSO surplus is positive and net efficiency is certain to increase. Exporting imbalances to less efficient regions with regard to system balancing, however, results in an efficiency loss for the TSO and can result in a negative net outcome. Indeed, both surpluses are of the same order of magnitude in the examined hypothetical cases. This result also holds more generally because, the UK and Belgian settlement mechanisms have been modeled accurately, the hypothetical cost parameters have been derived from real flexibility-cost data and multiple cost and RMP data have been tested. If the relative efficiency of the expensive region is low, forum shopping turns net surplus negative and thus reduces overall efficiency, but the transnational shippers always gain.

Gas-market regulators and policy makers need to be aware of the possibly efficiencyreducing framework of incompatible or non-harmonized non-market-based balancing mechanisms in geographically adjacent gas regions. Indeed, net efficiency (as a kind of welfare) should be their primary concern. Introducing market-based cross-border 
balancing with regard to procurement and settlement solves this problem because settlement is then directly linked to the effective imbalance position of the system. As a result, forum-shopping shippers affect the settlement tariff and while they might initially gain from exporting imbalances, the mechanism will correct itself and prices will provide correct signals to the TSO and the shippers. Steps towards market-based balancing are taken only slowly. One reason might be that the efficiency gain has to be distributed over the participating regions in a fair and coordinated manner. This might be difficult to implement because not all actors profit equally. Until that problem is resolved, shippers face potentially net-efficiency-reducing incentives. Indeed, the shippers can increase their individual profit at the cost of lowering efficiency of the community of network users, represented by the TSO.

Further research is necessary to understand all aspects of balancing-mechanism design in a multi-region gas market. In particular, the effect of ex-ante flexibility on balancing constitutes an interesting extension of the scope in this paper.

\section{Acknowledgement}

This paper has been written in the context of the project "Fundamental study of the macroscopic feed back loops and basic uncertainties in pipe and wired based unbundled energy markets with the aim of global, flexible optimization from different viewpoints" funded by Fonds Wetenschappelijk Onderzoek Vlaanderen (FWO).

\section{References}

ACER, 2011. Framework Guidelines on Gas Balancing in Transmission Systems. Agency for the Cooperation of Energy Regulators, Ljubljana.

APX ENDEX, 2012. www.apxendex.com.

Ascari, S., 2011. An American model for the EU gas market?, EUI Working Papers. EUI, San Domenico di Fiesole.

Ascari, S., Glachant, J.M., 2011. A Gas Target Model for the European Union: Contrasting MECOS and EURAM Proposal, in: Hallack, M., Vazquez, M. (Eds.), Policy Brief. EUI Florence School of Regulation, San Domenico di Fiesole.

Asche, F., Osmundsen, P., Sandsmark, M., 2006. The UK market for natural gas, oil and electricity: Are the prices decoupled? The Energy Journal 27, 27-40.

Asche, F., Osmundsen, P., Tveterås, R., 2002. European market integration for gas? Volume flexibility and political risk. Energy Economics 24, 249-265. 
Brown, S.P.A., Yücel, M.K., 2008. Deliverability and regional pricing in U.S. natural gas markets. Energy Economics 30, 2441-2453.

CEER, 2003. Principles for balancing rules. Council of European Energy Regulators, Brussels.

CEER, 2011. CEER vision for a European Gas Target Model: Conclusions paper. Council of European Energy Regulators, Brussels.

Clingendael International Energy Programme, 2011. CIEP Vision on the Gas Target Model, Clingendael Energy Paper. Clingendael International Energy Programme, The Hague.

Codognet, M.K., 2004. The shipper as the architect of contractual relations in access to natural gas networks, ISNIE 2004, 8th annual conference, Tucson, Arizona.

Codognet, M.K., 2006. L'analyse économique des contrats d'accès aux réseaux dans les réformes concurrentielles gazières, Doctoral dissertation. Université Paris Sud XI, Paris, France.

De Vany, A., Walls, W.D., 1996. The law of one price in a network: Arbitrage and price dynamics in natural gas city gate markets. Journal of Regional Science 36, 555-570.

Doane, M.J., Spulber, D.F., 1994. Open access and the evolution of the U. S. spot market for natural gas. Journal of Law and Economics 37, 477-517.

Eberhard, R., Hüning, R., 1990. Handbuch der Gasversorgungstechnik, Gastransport und Gasverteilung, 2 ed. Oldenbourg.

ERGEG, 2005. Gas balancing: an ERGEG discussion paper for public consultation. European Regulators Group for Electricity and Gas, Brussels.

ERGEG, 2006. Guidelines of good practice for gas balancing. European Regulators Group for Electricity and Gas, Brussels.

ERGEG, 2007. Impact assessment for guidelines on good practice for gas balancing. European Regulators Group for Electricity and Gas, Brussels.

ERGEG, 2008. Monitoring report: implementation of the ERGEG guidelines of good practice for gas balancing. European Regulators Group for Electricity and Gas, Brussels.

ERGEG, 2010. Gas balancing rules on European gas transmission networks: Draft pilot framework guideline. European Regulators Group for Electricity and Gas, Brussels.

ERGEG, 2011. Gas balancing in transmission systems: Framework guideline. European Regulators Group for Electricity and Gas, Brussels.

European Commission DG Competition, 2007. Report on the energy sector inquiry. European Commission, Brussels. 
FERC, 2000. Regulation of short-term natural gas transportation services, and regulation of interstate natural gas transportation services.

Fluxys, 2010. Programme indicatif d'acheminement 2011-2012.

Fluxys, 2011. Fluxys natural gas transport services in Belgium: Conditions \& Tariffs.

Fluxys, 2012. www.fluxys.com.

Frontier Economics, Stratorg, Ylios, 2011. Target Model for the European Natural Gas Market.

Glachant, J.-M., Hallack, M., 2009. Take-or-pay contract robustness: A three step story told by the BrazilBolivia gas case? Energy Policy 37, 651 - 657.

Glachant, J.M., 2011. A vision for the EU gas target model: The MECO-S model, EUI Working Papers. EUI, San Domenico di Fiesole.

Glachant, J.M., 2012. A 'Target Model' for the Internal Gas Market, FSR Webinars. EUI Florence School of Regulation.

GTE, 2001. GTE balancing and storage report. Gas Transmission Europe, Brussels.

GTE, 2005. Comments on ERGEG "gas balancing" discussion paper. Gas Transmission Europe, Brussels.

GTE, 2009. Report on a benchmark among GTE members to assess difficulties in the application of the current GGP on gas balancing. Gas Transmission Europe, Brussels.

GTS, 2012. www.gastransportservices.nl.

Hallack, M., 2011. Economic Regulation of Offer and Demand of Flexibility in Gas Network, Doctoral dissertation, Faculty of economics. University of Paris Sud XI, Paris, France.

Hallack, M., Keyaerts, N., Bonafé, E., 2010. Conclusions of the "specialised training on regulation of gas markets", in: Florence School of Regulation (Ed.), Training conclusions. EUI-RSCAS, Florence.

Jansen, J.C., van Arkel, W.G., Boots, M.G., 2004. Designing indicators of long-term energy supply security. ECN.

Joint Office of Gas Transporters, 2013. Uniform Network Code v4.18, v4.18 ed.

Juenger, F.K., 1989. Forum shopping, domestic and international. Tulane Law Review 63, 553-574.

KEMA, 2007. Der deutsche Regel- und Ausgleichsenergiemarkt Gas im Rahmen des neuen Energiewirtschaftsgesetzes und des darauf aufbauenden Gasnetzzugangsmodells. Report commissioned by Bundesnetzagentur.

KEMA, 2009. Study on methodology for gas transmission network tariffs and gas balancing fees in Europe. Report for European Commission DG Transport and Energy. 
Keyaerts, N., 2012a. Gas Balancing and Line-pack Flexibility. Concepts and Methodologies for Organizing and Regulating Gas Balancing in Liberalized and Integrated EU Gas Markets., Doctoral dissertation, Faculty of Engineering. KU Leuven Leuven.

Keyaerts, N., 2012b. Using operations research to study optimal use of flexibility in liberalizing gas markets: GASFLEX, TME Working paper series. University of Leuven (KU Leuven) Energy Institute.

Keyaerts, N., Hallack, M., Glachant, J.-M., D’haeseleer, W., 2011. Gas market distorting effects of imbalanced gas balancing rules: Inefficient regulation of pipeline flexibility. Energy Policy 39, 865-876.

Lise, W., Hobbs, B.F., van Oostvoorn, F., 2008. Natural gas corridors between the EU and its main suppliers: Simulation results with the dynamic GASTALE model. Energy Policy 36, 1890-1906.

Moselle, B., White, M., 2011. Market design for natural gas: the Target Model for the Internal Market. LECG, London.

National Grid, 2012a. Default System Marginal Price Statement 31 July 2012.

National Grid, 2012b. www.nationalgrid.com/uk/Gas.

NERA, TPA Solutions, 2005. Gas balancing rules in Europe, Report commissioned by CREG.

Neumann, A., Siliverstovs, B., Hirschhausen, C.v., 2006. Convergence of European spot market prices for natural gas? A real-time analysis of market integration using the Kalman Filter. Applied Economics Letters $13,727-732$

Stern, J., 2009. Continental European long term gas contracts: Is a shift away from oil-linked pricing inevitable?, Oxford Institute for Energy Studies Working Papers. OIES, Oxford, p. 29.

Thomson Reuters, 2011. Datastream. Thomson Reuters, New York.

Vandezande, L., 2011. Design and integration of balancing markets in Europe, Doctoral dissertation, Faculty of Engineering. K.U. Leuven, Leuven, Belgium.

Vandezande, L., Saguan, M., Meeus, L., Glachant, J.M., Belmans, R., 2009. Assessment of the implementation of cross-border balancing trade between Belgium and the Netherlands, 6th International Conference on the European Energy Market (EEM), Leuven, pp. 1-6.

von Hirschhausen, C., Neumann, A., 2008. Long-term contracts and asset specificity revisited: An empirical analysis of producer-importer relations in the natural gas industry. Rev. Ind. Organ. 32, 131-143.

WMWG, 2010. DPM Biedladder v2.0. GTS Werkgroep Marktmodel Wholesale Gas. 


\section{Appendix - Gas-system data}

Table A1: Nodal information for network of Fig. 2: nodal-pressure limits, presence of compression and the maximal compression ratio and function of node in network

\begin{tabular}{llll}
\hline \hline Node & $\begin{array}{l}\text { Pressure } \\
\text { (low/high) [bar] }\end{array}$ & $\begin{array}{l}\text { limits } \\
\text { (ratio of outlet over } \\
\text { inlet pressure) }\end{array}$ & $\begin{array}{l}\text { Function: demand (D), supply (S), } \\
\text { transit (T), upward flexibility (F+) } \\
\text { or downward flexibility (F-) }\end{array}$ \\
\hline 1 & $60 / 80$ & $\mathrm{y}(1.33)$ & $\mathrm{S}$ \\
2 & $60 / 80$ & $\mathrm{n}$ & $\mathrm{D}$ \\
3 & $60 / 80$ & $\mathrm{n}$ & $\mathrm{D}$ \\
4 & $60 / 80$ & $\mathrm{n}$ & $\mathrm{F}+/ \mathrm{F}-$ \\
5 & $60 / 80$ & $\mathrm{y}(1.33)$ & $\mathrm{S}$ \\
6 & $60 / 80$ & $\mathrm{n}$ & $\mathrm{D}$ \\
7 & $60 / 80$ & $\mathrm{n}$ & $\mathrm{D}$ \\
8 & $60 / 80$ & $\mathrm{n}$ & $\mathrm{F}+/ \mathrm{F}-$ \\
\hline \hline
\end{tabular}

Table A2: Pipelines of network of Fig. 2: diameter $D$, distance $L$ and starting average pressure (to determine starting level of line pack)

\begin{tabular}{llll}
\hline \hline Pipeline & $\mathrm{D}[\mathrm{m}]$ & $\mathrm{L}[\mathrm{km}]$ & $\overline{\mathrm{p}}_{\text {a(j),start }}[$ bar $]$ \\
\hline $1-2$ & 1.85 & 60 & 70.47 \\
$2-3$ & 1.85 & 50 & 70.47 \\
$2-4$ & 1.85 & 5 & 70.47 \\
$5-6$ & 1.85 & 60 & 70.47 \\
$6-7$ & 1.85 & 50 & 70.47 \\
$6-8$ & 1.85 & 5 & 70.47 \\
\hline \hline
\end{tabular}

Table A3: Storage details of network of Fig. 2: base gas that remains in storage, working-gas capacity that can be filled and emptied and injection and withdrawal limits

\begin{tabular}{llllll}
\hline \hline Node & $\begin{array}{l}\text { Base gas } \\
{\left[\mathrm{M} \mathrm{m}^{3}\right]}\end{array}$ & $\begin{array}{l}\text { Working } \\
\text { (start) }\left[\mathrm{M} \mathrm{m}^{3}\right]\end{array}$ & gas & $\begin{array}{l}\text { Injection limit } \\
{\left[\mathrm{M} \mathrm{m}^{3} / \mathrm{h}\right]}\end{array}$ & $\begin{array}{l}\text { Withdrawal limit } \\
{\left[\mathrm{M} \mathrm{m} \mathrm{m}^{3} / \mathrm{h}\right]}\end{array}$ \\
\hline Storage 4 & 26 & $78(20)$ & 0.56 & 0.7 \\
Storage 8 & 26 & $78(20)$ & 0.56 & 0.7 \\
\hline
\end{tabular}

